\title{
Le Malaga Faigatā: Misadventures of An Accidental Academic
}

\author{
Roannie Ng Shiu, Fetaui Iosefo
}

\author{
E lele le toloa, ae ma'au i le vai
}

The toloa will fly far and wide, but will always return to the water-Samoan proverb

In my doctoral thesis, I examined the barriers to and enablers of academic success for Pacific tertiary health students at the University of Auckland. Ten years on, now back at the University of Auckland, I find myself again reflecting on the barriers to and enablers of academic success for Pacific academics. This reflection piece stems from a seminar I gave for the University of Auckland's Pacific Research Hub, entitled "Constructing Resilience: Lessons from An Accidental Pacific Academic." Initially, I was only going to speak to my current research project on Pacific youth resilience. But I was encouraged to share my experiences as a Samoan researcher and academic, especially for early career researchers. I therefore decided to use the seminar as a talanoa to share my experiences and have an honest discussion about some of the challenges that we, as Pacific researchers, experience within the academy. Rather than trying to sell a fairy tale, I decided to use the opportunity for real talk, sharing some of the things I wish someone had told me before I went down the academic path.

\section{In the Beginning}

My academic adventure began by accident. After three and a half years at university completing my conjoint degree, I decided it was time for me to return home to Sāmoa and use my newfound knowledge and energies to serve my country and the region through the United Nations graduate program. I travelled to Sāmoa and had a successful interview with the UNESCO office. My dad then said, "if you do your master's, I'll let you go with my blessing." So, what was a diligent and dutiful Sāmoan daughter to do, except turn down an amazing opportunity to continue more study to get her father's blessing.

Not long after my interview in Sāmoa, I was asked to consider a Pacific master's scholarship to study social science and health. I had not really considered health as a study area, and was in fact writing up a thesis proposal on Pacific development. I had done well in a postgraduate health geography course, and the lecturer, Dr Robin Kearns, had always been supportive, and they were struggling to find a Pacific student, so I said yes.

During my two years completing my masters, there were hospitalisations, weddings, babies, funerals, none of which were mine. But somehow, these all took up so much of my time. It was difficult to explain to others, who had no reference point, the concept of independent selfdirected study. The time and cost of getting to university meant working from home was easier, but then when you are mostly working from home everyone assumes you are free to be taxi driver, cleaner, or Sunday school teacher, because if you are not at university for classes, are you really studying? Add to the mix actual academic drama, including supervisor musical chairs and interview recordings getting stolen from a car break-in, at one point I asked myself, "what am I doing here?" "That's right, getting Dad's blessing." I survived that adventure and was surprised to pass with honours; I knew I could have done so much better with a bit more time. Nonetheless, with my new piece of paper, I was ready to embark on my real adventure and vowed never to go back to university ever again.

Plot twist: not long after graduating with my masters, I ended up back at the University of Auckland but this time as a researcher with Pacific Health at the Faculty of Medical and Health

Journal of New Zealand Studies NS33 (2021), 153-161 https://doi.org/10.26686/jnzs.iNS33.7389 
Sciences. This connection was again through Dr Robin Kearns. And again, they were struggling to find Pacific health researchers for Pacific research projects. It was a short-term contract, and it was halfway through the year, so I said yes while I worked out my real plan A.

But I loved it. It was not until I joined Pacific Health at the School of Population Health that I found what was missing in terms of my academic journey: a place where I felt I belonged. I must acknowledge that up until this time the human geography department had been good to me, and I thoroughly enjoyed my experience there with amazing academics who had championed me all throughout my undergraduate and master's journey. But at Pacific Health I felt even more at home. At the time it was led by Dr Collin Tukuitonga and every person that worked there came from a Pacific background. It was not all perfect; there were always resourcing issues, the occasional staff conflict and project delays. But I found myself thriving. I worked on two Pacific health workforce development contracts for the Ministry of Health with teams of mostly Pacific researchers.

With some tough talk and boundless encouragement, I applied for a Health Research Council (HRC) scholarship, focusing on Pacific health workforce development. This time I carried on with my postgraduate study, not for Dad or anyone else, but for me.

My doctoral experience was literally the best time of my life, with a great supervision team including Dr Janine Wiles, Dr Collin Tukuitonga, and Malepeai Dr Ieti Lima. Before applying for the HRC scholarship, I did have one academic who was pessimistic about doctoral study, and who questioned a few times whether I was ready or capable of completing: "are you sure you really want to do this? Do you think you can finish, it's really hard." After my master's experience, it really did sow seeds of doubt, but I'm glad I listened to everyone else and not the one naysayer. But it goes to show how much influence one negative comment can have on a person's self-esteem, even when everyone else is positive. This experience, and my entire doctoral journey, has shaped my broader academic mission for Pacific capacity building, and for this reason I have always tried to be affirming and aspirational with all Pacific students who demonstrate the passion and capability for academic success. I know that highly motivated and capable students can thrive and succeed if they are given the right encouragement and have an enabling support system both at university and home.

Based on my postgraduate experience here are three things that I learnt:

1. Courageous conversations. Have honest and open conversations with your family about protecting your time to study, especially as a postgraduate student. In the broader scheme of things, the time spent on completing your studies is a short-term sacrifice from family commitments and community responsibilities for a long-term gain. During my doctorate, my family gave me a lot of room and space, having seen what I had gone through with my masters.

2. Find a topic that you are passionate about. I would recommend undertaking a postgraduate scholarship tied to a specific research project only if you are passionate about that topic or subject area. Postgraduate study is hard for a reason, and there will always be high and low points. Your passion for your topic is what will motivate you to get through the low points.

3. Find the right supervision team. Supervision is key, and you need to find the right balance for your team. For my doctorate I was fortunate enough to have great people for my university supervision team, and a broader advisory team that I was able to lean on for different aspects of my research. 


\section{My Australian National University Adventure}

In terms of an academic identity, I have always been drawn to human geography because it focuses on the intersections and relationships between place, space, the environment, and people. I appreciate the diverse theoretical and methodological approaches within human geography, and this would serve me well when I started my academic career at the Australian National University (ANU). Within my department, I held one of a few coveted permanent positions, and was one of a few Pacific academics across the entire university. This meant I ended up being involved in multiple projects ranging from cross-cultural training for Australian diplomats, election observation research in the Pacific region, cultural and education empowerment, and study tours in Sāmoa, Fiji, Papua New Guinea, New Caledonia, and the United States. I sat on endless committees as a Pacific representative, and as well I was involved in setting up partnerships and relationships with key stakeholders locally, nationally, regionally, and globally.

What I learnt through engaging with these partnerships is that it is much easier to build new bridges than to try to mend old ones. I found out the hard way that the adage of water under the bridge does not necessarily apply between the ivory tower that is the university and local Pacific communities. Being new to the academic scene and the community, I spent a lot of time building relationships and trying to regain trust. I gave countless community and church talks, went to every church denomination service, and sat on different community committees and councils. The only way that we were going to establish effective and sustainable outcomes was through partnership with all Pacific stakeholders.

Once you burn bridges with communities, it is hard trying to rebuild solid foundations and bridges out of ash. Trying to explain this to some academics in the ivory tower, I found they could not understand why Pacific people were upset at how they were trying to help Pacific communities by describing and sharing with them some of the truths and realities of living in the Pacific, based on their fieldwork and research.

At the same time, not all Pacific academics get along all the time, and we can be our own worst enemies. Having been nurtured through my whole university experience at the University of Auckland by a variety of academics Pacific, Pālāgi, men, women, geographers, behavioural scientists, doctors and so forth, I thought that this nurturing experience was universal. But transitioning from the role of student to academic is hard, and you soon find that liminal space that should be transformational as an early career academic can be isolating and a lot of hard work if you are not in the right environment.

The expectation that the generation before you were paving the way for you to follow and create a Pacific pipeline can sometimes be a pipedream. In Australia, there is so little Pacific capacity compared to New Zealand. Therefore, it was and remains important to work together to attract, retain and nurture Pacific talent and scholars. The total Pacific population in Australia is less than 1 percent, yet so much research in and about the Pacific comes from Australia. ${ }^{1}$ While at ANU, I always felt a Pacific academic who was raised in Australia would be best placed to work on domestic capacity-building projects, and in many respects, I was holding space while a new generation of Pacific Australian academics were coming through.

\section{Equity Tax}

In my experience, equity seems to be constantly misunderstood, often conflated with equality. Almost everyone in tertiary institutions believes and supports equity and Pacific equity - in principle. This is important. But when trying to implement equity programs at university, I 
have found it to be very difficult because the processes are not set up for equitable outcomes or, as Roos and Gatta describe, there are mechanisms of inequity. ${ }^{2}$ Discrimination is no longer overt; rather, there are subtle mechanisms that reproduce inequalities and inequities. Access and equity are complex issues, particularly as they pertain to legal definitions and employment law. For example, in your program and project you are given funds to help with Pacific capacity building, so you want to and need to hire a Pacific person for the job, but you cannot advertise for a Pacific Island scholar because this would be considered discriminatory. This problem is not limited to Australasia; it has been debated and discussed globally and is often discussed using varying terms, including the oxymoron "positive discrimination." Similarly, when it comes to assessing candidates for promotion, the main criteria is publishing in highly ranked journals, with teaching and service secondary considerations. The problem for Pacific academics is that the service component of their work is more significant than it is for most other academics, because they are always asked to sit on multiple committees to ensure Pacific representation. This is what $\mathrm{I}$ describe as the equity tax for minority academics. Because there are so few Pacific academics in the first place, those that are currently employed end up being stretched thin to provide fair representation for Pacific communities.

The simplest answer to equity tax is not to sit on these committees, but the trade-off is that there is no Pacific representation on important projects or core issues. In many situations university committee work takes up a lot of time for the greater good of Pacific academic advancement in general, but in many cases, for Pacific academics, this is a lose-lose situation for academic progression. You spend time helping the university meet its moral and equity obligations and responsibilities, but this service is rarely acknowledged or rewarded. On paper for promotions, it feels like invisible work. The equity tax is problematic when you are getting assessed in the same way as everyone else. The irony is that if all things were equal there would not be a need for equity programs in the first place.

\section{Competency Tax}

The equity tax is doubled if you are competent. In 2015 researchers from Duke University, the University of Georgia and the University of Colorado Denver published an article based on multiple studies demonstrating that people that have high self-control are relied on more at work and at home. ${ }^{3}$ This is what I like to describe as the competency tax. The study by Koval and colleagues shows that in any given academic department, the workload is shared unequally between faculty members, with some individuals asked to serve on more committees. While it may be great for employers and managers to have a "go to" person who is reliable, for the individual this overreliance becomes burdensome and again adds invisible work to an already demanding workload.

Some Pacific academics therefore face the double burden of an equity tax and a competency tax by being a competent and reliable team member. This competency tax for some Pacific academics compounds the negative implications for academic progression and is highlighted by the real life experience shared by Sisifia and Fifita in this issue. ${ }^{4}$ Throughout my academic journey I have faced this issue. I wish that early on in my career I had had a champion who could have helped me navigate academic politics and deflect some of the extra responsibilities and burdens that were not supposed to be mine to bear. Within months of my arrival at ANU, I was made convenor the Pacific equity program, ANU Pasifika Australia, and shortly thereafter I was given more responsibility, leading a pilot programme for digital innovation and online learning. I was then asked to take over and lead a key relationship which involved research and teaching collaborations. 
One of my most memorable experiences of the competency tax was being told that I was the new convenor of an undergraduate degree program while overseas in the middle of fieldwork through an all of faculty email. All these extra responsibilities were due to the non-performance of other academics, who were then able to have time to publish books and journal articles. This leads to the ironic situation of being great at your job without any reward, while those who are incompetent get rewarded with more time to progress their own academic careers. Managers were always sympathetic but did not know how to solve the problem, because they needed a job done and done well. There were always funding shortages, where we had to wait for others to retire to free up resourcing for postdoctoral researchers. I was always tempted to be like some of the others and just not perform, but my reputation means a lot to me.

\section{Advancing Pacific Peoples and Pacific Studies}

My Pacific equity experience in the Australian tertiary sector has been framed by affirmative action for Pacific peoples and increasing the visibility of Pacific studies as an academic discipline and program. Again, these two issues often get conflated. They are related but not necessarily the same. Take, for example, the Australian Association for Pacific Studies. I was first introduced to this association at one of their conferences, which was then called the Australian Association for the Advancement for Pacific Studies. I had no issue or problem with advancing Pacific studies in Australia, but I did have a problem with trying to advance Pacific studies ahead of Pacific peoples. At the conference I was told that "you, of all people should be in there and on the board." This made me very nervous and uncomfortable. I had only just arrived in Australia having completed my entire postgraduate education without a single Pacific studies specialty, major or minor. Within my academic disciplines, I had always focused on the Pacific region, peoples, and issues, but in terms of academic specialty I had never considered myself a Pacific studies academic; I was a Pacific academic. This was further highlighted later in my role leading the Pacific equity program for ANU. It was expected that my role in promoting higher education aspirations for Pacific students in Australia. also meant I was to recruit students and support all Pacific studies students at the university. One of the key problems was not the lack of aspirations for Pacific communities in Australia but the lack of resourcing. Many of the Pacific families in Australia had recently migrated from New Zealand and were still New Zealand citizens. This allowed them to pay domestic tuition fees, but meant that they had to pay the fees upfront as they were ineligible for any government support. How could I go out to the community and lecture them about the possibilities of a tertiary education without providing the financial support to get them there? The rules have changed now to help widen access to higher education, but at the time I felt I was doing a disservice to our community by promoting a pathway that was beyond the means of many.

Unlike the New Zealand education system, there is virtually no Pacific content in the secondary school curriculum. So trying to recruit students into Pacific studies was always going to be a challenge, without any exposure to Pacific content in Australian compulsory schooling. I found myself battling two different equity issues. First, there had been a suggestion that we make Pacific studies compulsory and that I was to try and push Pacific students into the Pacific studies programme. This was a very ill-conceived enrolment strategy, to say the least. I was just happy for any Pacific student to enrol in any program, given the small pool that we could potentially recruit from. Canberra is a government town with a small Pacific population, compared to the urban cities of Sydney, Melbourne, and Brisbane. We were trying to recruit students from a small base and attract students from the cities to travel to Canberra, leave their families and rent expensive student accommodation. With these parameters we were always going to have small numbers. But to then suggest all Pacific students should also enrol in 
Pacific studies was unfathomable. I was not going to push that agenda. Were students of Asian heritage meant to enrol in Asian studies, and all Australian students enrol in Australian studies?

The second issue was the use of limited Pacific equity resourcing to support any Pacific studies student. This again left me conflicted, when I felt I had to advance Pacific studies ahead of Pacific people. I would not do it. I am pro-Pacific studies, and I am encouraged by the fact that most Pacific students now enrol in at least one Pacific studies course. But this should not be forced. Within Pacific communities, both in Australia and the Pacific, there was always reluctance for Pacific students to engage in Pacific studies. They would ask "I'm Pacific, why would I come to university to do Pacific studies?" This was especially so for students who would come from the region and were very clear minded that they wanted to come to Australia and learn from the best in their chosen academic field. I have never met anyone from the region to date who applied to come to Australia to enrol in the Bachelor of Pacific Studies. I believed that our job was, first, to help students enrol at ANU, and then to articulate why Pacific studies is critical for their own development and for Pacific communities everywhere.

Rigorous debates on persisting inequities and on progressing Indigenous knowledge in Western universities needs to happen within universities and institutions and between all stakeholders before sustainable and transformational change can take place. There have been some shifts and gains towards decolonising knowledge in Western universities since Edward Said published his seminal piece Orientalism. ${ }^{5}$ Said's work underpinned my doctoral thesis and continues to influence my current practice and thinking. Closer to home, these struggles and key debates have been championed by leading indigenous scholars such as Dr Konai HeluThaman, Dr Linda Tuhiwai Smith, Dr Brendan Hokowhitu and the late Dr Teresia Teaiwa. Their influence can be seen in the ways that a new generation of Pacific scholars further expand and build on these fundamental debates.

\section{Returning to My University "Home"}

Now recently returned, I find myself wondering how the Faculty of Medical and Health Sciences is the same place that nurtured me as a doctoral candidate. My experience is not unique, and has in fact been replicated in many institutions with women in academia, as demonstrated by the MIT report on the status of women faculty in science from 1999. ${ }^{6}$ One of the key findings is that senior women often felt invisible and marginalised while junior women felt well supported. Senior women responded by saying they had once felt that way too when they were junior faculty. I, too, understand this readily, now. Trying to transgress mechanisms of subtle inequalities and progress academic Pacific representation can be overwhelming and overburdening.

During my time as a doctoral student, I had seen a steady pipeline of Pacific postgraduate students coming through and succeeding. In deciding to return and create a new Pacific team, I did not realise I would encounter so many problems, the least of which was the question, "where is everyone?" The underrepresentation of Pacific health workers and researchers is a persisting challenge that requires long-term systemic change to the entire education system. For the small number of Pacific health workers and researchers who are successful, there is no shortage of employment. Often, people are looking to hire and recruit the same talent from a very limited pool. The university faces the challenge of not being able to provide competitive salaries relative to the private sector and other public-sector organisations, including hospitals and the public administration. The offers from these organisations and from the private sector are significantly higher when you are talented and can fill the diversity quota. For instance, one master's graduate was earning more money in a graduate position within a New Zealand district 
health board than a postdoctoral fellow with a $\mathrm{PhD}$ at the university. Universities need to move away from their ivory-tower thinking if they want to retain the best Pacific talent. There will be those who will persist with academia and the university because of the research possibilities that universities offer. Those who do stay should feel valued and rewarded rather than fatigued from trying to advance an academic career while still contributing to equity efforts, including staying connected to their community.

After reading this, many might ask, why do you stay? The short answer is the academics in this special issue. In my time in academia, I have been lucky enough to engage with, support and work with inspiring Pacific leaders and talent who have gone on to leadership roles in their respective governments, as ambassadors for their countries, international diplomats and negotiators, and Pacific scholars. The challenge for me now is to try to transgress and transform all academic spaces so that the experiences of senior women in science at MIT and my current experience are lessons from the past. My hope is that there will be a transformational shift soon, to a situation in which all Pacific academics feel supported, no matter their position within their university.

I am honoured to be part of this issue in a small way with this next generation of transcending and transformational Pacific scholars in Aotearoa. They are what makes this unconventional academic journey special.

Ia manuia. Soifua.

\section{Le Taualuga ${ }^{7}$ (The Finale): As a Collective It Is Time}

Performed by Fetaui Iosefo

As the sun rises in the East our Moana is ready to greet our sun

Moana whispers to the sea of islands ala mai (wake up)

Each island connected to our Moananui-a-kiwa pays heed to her whisper

Our Moana specifically whispers to an emerging Samoan Pasifika, critical queer (re)searcher

\section{"The time is now to transform,}

To rely on the transcendence of your ancestors,

To transgress and reclaim, restore, reconcile who we are, As a collective it is time"

He responds with a swag, confident buoyant "Yes, it is!"

He calls to the collective "Ala mai, our Moana said it is time."

It is time to (re)claim unapologetically our Moana sensibilities Without western tools created to muzzle and silence our ancestors' divinities

For far too long we have limited our ability to transform

Instead, we conform, which leaves us

At the mercy of the prominent and dominant Our emerging (re)searcher identity is confined within western frames of reliability

Defaming our Moana Pasifika plurality The precarity of Moana diaspora scholars within academic spaces Whose brown boldfaces hide the traces of racist interfaces. Our emerging scholars look to the west and pray the sun will set On the pain of having to (re)claim 
Our diaspora emerging researchers' souls seek solace

Our bodies our minds crave to rejuvenate

Crave to recuperate in our Moana

Our Moana beckons us

She is ready to hold us

She is ready to wash our salty tears and fears

To replace our fear and tears with her pure healing water

As we bathe with her she reminds us

Of our Custodial duties to our Moana

She whispers:

"Go now my children the sun will set soon

Reclaim our tools of wayfinding,

Restore our su'ifefiloi methodology

Redeem our talanoa methodology;

Reconcile within our Vā;

The time is now to transform,

To rely on the transcendence of your ancestors To transgress and reclaim, restore, reconcile who we are, As a collective it is time"

A "Moana cosmopolitan" art creator and academic hears the whispering of the Moana. She looks at her hands and sees the marks of her ancestors and positions her body to face our Moana and in reverence nods in acknowledgement then skilfully and artistically stitches su'ifefiloi as methodology.

A female academic in sociology also hears the Moana whisper, she looks out to the Moana smiles, looks to her ancestors' markings on her thighs and in solemnity nods in acknowledgement, that she too will navigate gently and respectfully the gendered $v \bar{a}$.

Three Tongan academic males and one Tongan female academic collectively hear her, and together with their kāinga (family) pick up her tools of wayfinding and unapologetically reclaim lea faka Tonga within the poetics of the academy

Two wayfinding Pasifika emerging law academics wave out to Moana and respond with "we hear you and with the strength of our ancestors we will dare to create our own Pacific jurisprudence"

A Tongan female business academic adheres to the whispers and responds with a flick of her hair and a raise of her perfectly shaped eyebrow she winks and says "Talanoa? Ah huh, I got you"

Moana gestures to two queer scholars and says "Yes, you two it is time, to unapologetically challenge, provoke, and transgress western ideologies of Pasifika queer families and communities." 
Moana sees the Toloa academic flying between continents. She calls out to her "Toloa, my darling, it is time for you to come home." The academic Toloa ruffles her feathers and asks "really, why?" Moana replies "You have learnt so many things in your adventures and misadventures and now it is time to use all you have learnt to help your Moana Pacific." Moana continues "Toloa, your heart is pure, and with your spirit of generosity and service it is time to return home to the collective it is time ..."

\section{Our Moana continues to whisper to those who are willing to listen "The time is now \\ To transform, \\ To rely on the transcendence of your ancestors \\ To transgress and reclaim, \\ To restore, \\ To reconcile \\ Unapologetically \\ Who we are, \\ As a collective \\ It is time"}

\footnotetext{
${ }^{1}$ James Batley, "What Does the 2016 Census Reveal about Pacific Islands Communities in Australia?" State, Society, and Governance in Melanesia Program, Australian National University, 2017, https://openresearchrepository.anu.edu.au/bitstream/1885/141377/1/IB2017.23\%20James\%20Batley.pdf. ${ }^{2}$ Patricia A. Roos and Mary L. Gatta, "Gender (In)Equity in the Academy: Subtle Mechanisms and the Production of Inequality," Research in Social Stratification and Mobility 27, no. 3 (2009): 177200.

${ }^{3}$ Christy Zhou Koval et al., "The Burden of Responsibility: Interpersonal Costs of High Self-control," Journal of Personality and Social Psychology 108, no. 5 (2015): 750-66.

${ }^{4}$ See Sisikula Sisifa and 'Ilaisaane Fifita, "Burdened in Business: Pacific Early Career Academics Experiences with Promoting Pacific Research Methodologies in the Business Academy," in this issue of Journal of New Zealand Studies.

${ }^{5}$ Edward Said. Orientalism: Western Concepts of the Orient (New York: Pantheon, 1978).

${ }^{6}$ Committee on Women Faculty in the School of Science, "A Study on the Status of Women Faculty in Science at MIT," MIT Faculty Newsletter 11, no. 4 (1999): 415.

${ }^{7}$ A taualuga is the crowning of a gathering in Samoan cultural custom, usually performed as a dance with entire families and villages supporting in the back, as the taupou or manaia, the chief's daughter or son, takes centre stage. A taualuga celebrates relationships that have been renewed in the vā, in presenting one's pride in the hosting of a successful event, in honouring the genealogies everyone carries into the space of meeting, discussion, and celebration. This special issue ends with a poetic taualuga, which crowns the mana and beauty of all that has been shared between us in this special issue and points to the powerful potential in acknowledging that there are multiple ways forward for Pacific research and Pacific early career researchers in our country today and into the future.
} 